\title{
Scratch como recurso pedagógico para o ensino de modelos atômicos na modalidade médio-técnico: uma contribuição do construtivismo de piaget
}

\section{Scratch as a pedagogical resource for teaching atomic models in medium-technical modality: a contribution of piaget's constructivism}

\author{
João Batista Félix de Sousa ${ }^{1 *}$, Marcela dos Santos Barbosa ${ }^{2}$, Lucas Antunes Tenório ${ }^{3}$, Marisa \\ Almeida Cavalcanter ${ }^{4}$
}

\begin{abstract}
RESUMO
O estudo de atomística no primeiro ano do ensino médio é importante para o entendimento de outros conteúdos de química que serão futuramente ensinados. Nesse seguimento, quando a aprendizagem se concretizar serão desenvolvidos os processos de assimilação, acomodação e equilibração, como aborda a teoria construtivista de Jean Piaget. Dessa forma, com o objetivo de contribuir com o processo de equilibração no aprendizado de atomística, este trabalho apresenta uma proposta na qual utilizou-se como ferramenta didática o programa Scratch, durante uma oficina de atividades práticas no computador, em que os alunos tiveram que ser ativos e criativos. A oficina foi realizada com 9 alunos do $1^{\circ}$ ano do ensino médiotécnico do curso Técnico em Desenvolvimento de Sistema, localizado no Instituto Federal do Amazonas (IFAM), Campus Presidente Figueiredo. Os resultados evidenciam que o Scratch contribuiu para o aprendizado de modelos atômicos e de programação. Este trabalho poderá ser utilizado como instrumento didático-pedagógico para aulas de ciências, sendo facilmente adaptável e atendendo aos interesses de todos os envolvidos no processo de ensino e aprendizagem.
\end{abstract}

Palavras-chave: Jean Piaget; Modelos atômicos; Ensino e aprendizagem;

\begin{abstract}
The study of atomistics in the first year of high school is important for understanding other chemistry content that will be taught in the future. In this segment, when learning takes place, assimilation, accommodation and equilibrium processes will be developed, as discussed by Jean Piaget's constructivist theory. Thus, in order to contribute to the process of balancing atomistic learning, this work presents a proposal where the Scratch program was used as a didactic tool, during a workshop of practical activities on the computer, in which students had to be active and creative. The workshop was held with 9 students from the 1st year of technical high school of the Technical course in System Development, located at the Federal Institute of Amazonas (IFAM), Campus Presidente Figueiredo. The results show that Scratch contributed to the learning of atomic models and programming. This work can be used as a didactic-
\end{abstract}

\footnotetext{
${ }^{1}$ Instituto Federal do Amazonas (IFAM).*E-mail: joaomestrando5@gmail.com

${ }^{2}$ Universidade Federal do Amazonas (UFAM)

${ }^{3}$ Universidade Paulista (UNIP)

${ }^{4}$ Universidade Federal do Amazonas (UFAM)
} 
pedagogical tool for science classes, being easily adaptable and meeting the interests of everyone involved in the teaching and learning process.

Keywords: Jean Piaget; Atomic models; Teaching and learning

\section{INTRODUÇÃO}

Scratch é um software criado para auxiliar no processo de ensino-aprendizagem de programação, por meio dele os usuários fazem o uso da criatividade para desenvolver simulações, jogos e vídeos, por isso é comumente visto como ferramenta na ação docente em diferentes atividades escolares, favorecendo o desempenho do discente e contribuindo com sua percepção durante a aquisição do conhecimento.

As ferramentas didáticas e tecnológicas podem atuar integradas nos processos de ensino e aprendizagem, tornando-se responsáveis pelo desenvolvimento da capacidade cognitiva dos estudantes nos espaços escolares. Neste artigo consideramos o uso do Scratch como ferramenta para o aprendizado de atomística, ou seja, o estudo dos modelos atômicos e das partículas subatômicas do átomo, numa turma de primeiro ano de um curso médio-técnico de análise de Sistema, portanto, visamos identificar o aprendizado do tema proposto por meio da criatividades dos participantes ao utilizar o Scratch.

O Scratch aprimora a criatividade dos estudantes, fazendo-os desenvolver inúmeras criações lúdicas. O processo de invenção contribui com a capacidade cognitiva, raciocínio lógico e imaginação, despertando habilidades e competências em programação e temáticas educacionais, quando é utilizada em escolas, mostrando-se como ferramenta necessária para a práxis docente.

Em relação ao tema de atomística, que será o foco de investigação nesse trabalho, pode-se dizer que é considerado importante uma vez que é o conteúdo básico para o entendimento da disciplina de química. Geralmente, a atomística é apresentada em aulas comumente tradicionais, onde dificilmente são realizadas atividades práticas.

Apesar da crescente utilização do Scratch em espaços formais de ensino e pesquisas que o exploram no âmbito educacional, quase não há publicações referente ao aprendizado de química, em especial atomística, resultando na necessidade dessa plataforma ser mais explorada em disciplinas científicas. Ademais, é mostrado que a maioria das práticas pedagógicas com recursos tecnológicos como o Scratch não são 
sustentadas com teorias construtivistas, que são importantes para oferecer um suporte teórico na realização das atividades didáticas, orientando na organização e planejamento da metodologia, além de dispor de soluções para auxiliar no aprendizado.

Dessa forma, esse artigo propõe apresentar resultados de uma aplicação experimental com o programa Scratch, instituído em um conjunto de critérios para a análise da prática, fundamentada no construtivismo de Jean Piaget. A pesquisa busca preparar os alunos com oficinas sobre o Scratch para auxiliá-los no entendimento sobre modelos atômicos e também programação. As oficinas são importantes para o desenvolvimento de competências, habilidades, autonomia e comunicação. Além disso, as características de adaptação oferecidas na oficina Scratch podem ser aplicadas para diferentes disciplinas escolares.

Este trabalho está estruturado da seguinte maneira: a Parte 1 foi a introdução, a Parte 2 apresenta a fundamentação teórica, na Parte 3 tem-se os métodos utilizados na pesquisa, na Parte 4 temos os resultados e discussões e na Parte 5 as considerações finais.

\section{FUNDAMENTAÇÃO TEÓRICA}

Nesta sessão é realizado um apanhado teórico sobre os principais conceitos da vasta obra de Piaget, além de pesquisas que possuem relação com práticas ativas no Scratch, realizadas por estudantes no ensino básico, em especial fundamental e médio.

Piaget (1972) foi um biólogo suíço de ampla formação e áreas de interesse, tendo passado também e, sobretudo, pela filosofia e psicologia. Desde muito cedo já demonstrava sua genialidade precoce chegando a trabalhar em um museu aos onze anos e, aos quinze, já era reconhecido como especialista na classificação de moluscos. Ademais, seu interesse igualmente precoce em filosofia o levou a ter contato desde o início com obras de Henri Bergson, implicando no que veio a ser a premissa de todo o seu arcabouço teórico (PIAGET, 1972).

O questionamento que permeia e alicerça a construção do pensamento piagetiano é, portanto, referente à gênese do conhecimento e sua relação com um estado de equilíbrio (a princípio, biológico). As observações já assinaladas por Piaget enquanto biólogo se enlaçam às descobertas do estudioso de filosofia e encontram subsídios na psicologia do desenvolvimento, cuja busca pelo modo como se constrói conhecimento o leva aos 
experimentos e estudos com crianças, e cujo resultado é a formulação do construtivismo e de sua psicogênese, postulada em 1950 (Gauthier \&Tardif, 2017).

Piaget (1972) preconizava que a mesma premissa a qual obedece ao mecanismo de desenvolvimento da inteligência e aquisição do conhecimento é aquela já observada nos estudos com moluscos em sua carreira como biólogo, bem como é na mesma medida em que foi também postulada desde seus fundamentos no Élan vital de Bergson. A fonte cujo afluxo é inerente a todos esses derivativos é a busca pelo equilíbrio. Piaget se mostra então peremptório ao afirmar que o processo de construção do conhecimento tem seu início com um desequilíbrio, incitado por uma inadaptação do organismo ao meio; que, em termos de inteligência, busca sua supressão na aquisição de um conhecimento cada vez mais adequado às exigências de adaptação por parte do meio. Dito isto, o ser humano há de passar então por uma gradativa linhagem de sucessão que se dá em dois campos: de um lado esse processo se estabelece por meio de mecanismos que se dão de modo sucessivo, indissociável e cíclico, conceituados como assimilação e acomodação, cujo objetivo consiste na adaptação daquele estado inicial assolado pela desordem (conceito mais conhecido como equilibração); de outro, há de se passar por uma sucessão de fases, cada uma responsável por um determinado conjunto de aprendizados.

O processo supracitado consiste no que foi chamado ao longo da obra piagetiana de Schéme (esquemas/esquemas de ação), segundo o qual, seriam ações ou saberes basilares que pudessem ser transportáveis, generalizáveis ou imbuídas de distinguir um conhecimento prévio entre um estágio e o estágio ulterior. Seria o núcleo comum à diversas repetições ou aplicações da mesma ação ou derivadas desta, que através dos processos de assimilação e acomodação tornam a inteligência do indivíduo cada vez mais sofisticada, sendo também, cada vez menos generalizável na medida em que se torne mais desenvolvido (Carvalho Jr \& Parrat-Dayan, 2016).

Estas fases ou estágios são dispostas em quatro momentos, cada um referente a um determinado período e responsável por aprendizados específicos. Podem ocorrer pequenas variações cronológicas, mas a ordem das aquisições é universal (todos os indivíduos seguem a mesma sequência, embora possa haver variação em relação às idades) e cada estágio de desenvolvimento sucede o anterior sem anulá-lo, mas somandose a ele e a partir dele. Conforme Garcia (2010) seguem-se então da seguinte maneira:

Entre o nascimento e os dois anos de idade, a criança passa por um período chamado sensório-motor. Nessa fase o bebê constrói seu conhecimento de mundo através 
de percepções sensoriais e da motricidade. Trata-se de uma inteligência prática, pela qual a criança coordena seus esquemas no plano da ação.

Essa inteligência passa por um salto no período seguinte. O período préoperatório, que avança até por volta dos seis ou sete anos, graças à aquisição da linguagem permite que a criança expanda sua inteligência em relação a atributos relacionados a função semiótica, permite operações envolvendo a ideia de representação e substituição, mas é também um período caracterizado por um pensamento "egocêntrico", visto que, devido à sua ainda limitada cognição a criança apresenta dificuldades para operar fora do seu ponto de vista, operação esta que será possível apenas no estágio seguinte.

Entre aproximadamente os seis ou sete aos onze ou doze anos, a criança adentra no campo do pensamento lógico. É capaz de pensar logicamente sobre operações realizadas no campo do concreto inaugurando agora a possibilidade de reversibilidade nas operações lógicas. Não pode elaborar, no entanto, hipóteses sobre aquilo o que não lhe é de conhecimento prático. Período que por isso é conhecido como operatório concreto.

A partir de aproximadamente onze ou doze anos, o indivíduo passa então para o último estágio. $\mathrm{O}$ das operações formais, ou lógico-formal. Nesse período a estrutura cognitiva do adolescente já se assemelha a dos adultos, embora necessite maturação. A lógica, agora amplamente desenvolvida é finalmente capaz de pensar de forma abstrata, de entender expressões em sentido figurado, de definir e articular conceitos e refletir sobre os próprios pensamentos, podendo se questionar sobre possíveis falhas, equívocos e contradições. Pensamento que se caracteriza também como hipotético-dedutivo, ao contrário do período anterior, que se limitava ao aspecto indutivo (Lima, 1980).

Ademais, esse estágio é responsável por propiciar também uma estrutura de pensamento que articule conceitos complexos de matemática, abstrações filosóficas, aptidão para a ciência e, como diz Piaget (1972), num período mais especificamente entre quinze e vinte anos, a própria especialização profissional e diversas aptidões do indivíduo sofisticado de acordo com suas atividades particulares.

Outro conceito de demasiada influência na obra de Piaget é o das abstrações, empíricas e reflexionantes. Estes se referem ao modo como o sujeito retira do meio aquilo que lhe constituirá o aprendizado. Isso ocorre basicamente de duas maneiras: por meio das abstrações empíricas, o indivíduo age sobre os objetos, e retira um certo aprendizado através desta ação; as abstrações reflexionantes, já implicam numa reflexão sobre estas 
ações. É o pensar sobre o seu agir-no-mundo. O reflexo disso se dá na criação de esquemas. Na medida em que o sujeito age e abstrai da ação motora, reflete sobre estas ações, bem como sobre seus demais atos, motores ou não, sensíveis ou não, formam-se os esquemas de ações, possibilitando os sucessivos processos de assimilação e acomodação. Em suma, abstração empírica é aquela que ocorre num plano da experiência física, na interação com propriedades como cor, textura, forma, peso. Enquanto as abstrações reflexionantes referem-se à coordenação das ações, envolvendo a atuação da lógica e um reordenamento dos esquemas de ação já conhecidos para o desenvolvimento de novas habilidades adaptativas (Mantoan, 1994).

É importante frisar que os diversos conceitos supracitados atuam de modo conjunto, indissociável, concomitantes ou não, mas sempre de modo a constituir uma compreensão sobre aquele que foi o grande questionamento norteador da obra de Piaget (como se desenvolve a inteligência?) evidenciando, portanto, que a psicologia do autor não se limita a uma psicologia da criança, mas dirige-se ao desenvolvimento da inteligência humana de um modo geral, opondo-se às concepções empiristas e racionalistas. Esta é a resposta de Jean Piaget ao antigo debate epistemológico.

O construtivismo, portanto, instaura uma concepção humanista no processo de ensino-aprendizagem, colocando o aluno como centro deste processo, enquanto o professor se torna um facilitador, imbuído de colocar diante dos alunos um contexto favorável para a construção de seus próprios conhecimentos, permitindo que enfrentem obstáculos, errem e em participação conjunta com o docente desenvolvam a atividade construtiva (Gauthier \& Tardif, 2017).

O construtivismo não almeja ser um método; não impõe um modelo de ensino, ao contrário, questiona-o. Apresenta-se como atividade subjacente, cuja prática reflexiva se dá através da própria concepção epistemológica-genética. Não apresenta aos docentes um manual de ensino, mas o dota de uma compreensão e conduta propulsora para o seu fazerse docente, com toda a riqueza que este vocábulo carrega.

\section{SCRATCH NO ENSINO DE CIÊNCIAS}

O Scratch foi concebido baseado nas ideias construcionistas dos aplicativos Logo e Etoys (MALONEY et al., 2010). A programação é feita pela junção de blocos de comandos coloridos para controlar objetos gráficos 2-D que se movendo em um fundo 
chamado de palco. Projetos Scratch podem ser salvos localmente no computador ou compartilhado on-line no site do Scratch.

Com o Scratch o estudante assume a responsabilidade sobre o processo de aprendizagem, pois será capaz de resolver problemas, desenvolver projetos, ter postura mais participativa e propiciar meios para que ele seja o sujeito capaz de criar oportunidades para a construção do seu conhecimento. Ademais, ao utilizar o Scratch o professor deixa de ser somente o agente transmissor de conteúdos e passar a ser o mediador no processo de aprendizagem (Moran \& Valente, 2011), dispondo de orientações aos aprendizes, sem interferir na relação aluno-aluno.

Baytak e Land (2011) fizeram o uso do Scratch para ensinar sobre conceitos ambientais. A pesquisa foi aplicada com alunos do $5^{\circ}$ ano do fundamental e o Scratch os foi apresentado por meio de oficinas, o que os permitiu conhecer o programa e desenvolver jogos sobre o meio ambiente. A pesquisa foi significativa para os alunos, que puderam entender os conceitos estudados por meio da produção de suas ideias. Da Costa et al. (2016) também fizeram o uso do Scratch com o objetivo de ensinar educação ambiental, mas dessa vez a pesquisa foi realizada numa turma de ensino médio.

Nascimento e Costa (2017) fizeram o uso do Scratch para favorecer o aprendizado no conteúdo de nomenclatura dos hidrocarbonetos. A pesquisa foi aplicada para alunos do $3^{\circ}$ ano do Ensino Médio e os alunos foram ativos no processo de aprendizado. De Medeiros (2018) também fez o uso do Scratch para ensinar sobre hidrocarbonetos, porém ele explorou a temática de combustível, e assim os alunos tiveram que desenvolver jogos ou simulações acerca desse tema. Os resultados mostraram que a aprendizagem foi significativa, ocasionando na confecção de cinco produções: o jogo "Pelas trilhas do petróleo"; Órion; Maria Gasolina; Petrus; AlphaScratch; QuimScratch e Petrolândia.

Já Moura (2020) utilizou o Scratch para auxiliar no aprendizado de física, explorando os conteúdos de pressão, volume e temperatura numa turma de $2^{\circ}$ ano do ensino médio. A pesquisa apresentou bons resultados e os alunos foram ativos no processo de aprendizado e no desenvolvimento de simulações e animações. A pesquisa foi significativa pois os temas trabalhados foram relacionados com situações comuns no cotidiano deles.

Embora o Scratch tenha sido feito para que crianças e adolescentes desenvolverem ideias, animações e jogos criativos e divertidos, algumas pesquisas apresentadas a seguir 
mostram o contrário, sendo o professor o produtor das criações, mas apesar disso é verificado aprendizado (MALONEY et al., 2010).

Cordoba e Garcia (2017) desenvolveram um jogo no Scratch sobre reações químicas, para ser aplicado no ensino fundamental. O jogo apresentou bons resultados e os alunos assimilaram o conteúdo apresentado. Barreto, Da Silva, Giacomini e Cardoso (2017) fizeram o uso de um jogo chamado forca quis-química para contribuir no aprendizado dos elementos da tabela periódica, fórmulas e equações químicas. O jogo foi aplicado num curso técnico de química e os alunos assimilaram os conceitos brincando. Já Conceição e Vasconcelos (2018) desenvolveram um jogo sobre célula vegetal para ser aplicado numa turma do sétimo ano do ensino fundamental: os resultados foram bons e apontaram entendimento na estrutura celular.

\section{PROCEDIMENTOS METODOLÓGICOS}

A pesquisa retratada dispõe de uma abordagem qualitativa e descritiva, e explora a identificação das subjetividades e características de aprendizagem dos sujeitos investigados. Isto posto, pretendemos caracterizar a assimilação, acomodação e equilibrarão durante oficinas de criatividade com o Scratch, no ensino de modelos atômicos.

A metodologia foi organizada em quatro períodos. O primeiro foi a definição de um esboço didático para caracterizar os processos de construção do conhecimento de Piaget nas oficinas de Scratch, em seguida, foi apresentado como foram organizadas as oficinas, seguido da descrição dos participantes da pesquisa. No último momento é mostrado o procedimento estabelecido para a coleta dos resultados.

\section{ESBOÇO DIDÁTICO}

Partindo da premissa de que o conhecimento se dá de modo centrado no aluno e que este é o principal autor desse percurso construtivo, a Figura 1 visa esquematizar todo o processo tal como aplicado durante o experimento, relacionando cada etapa com a teoria de Piaget, com o objetivo de ilustrar a evolução resultante do manuseio do Scratch e de construir um conhecimento mais elaborado sobre modelos atômicos. 
Figura 1 - Esquema do esboço didático para o desenvolvimento da assimilação, acomodação e equilibração na oficina Scratch.

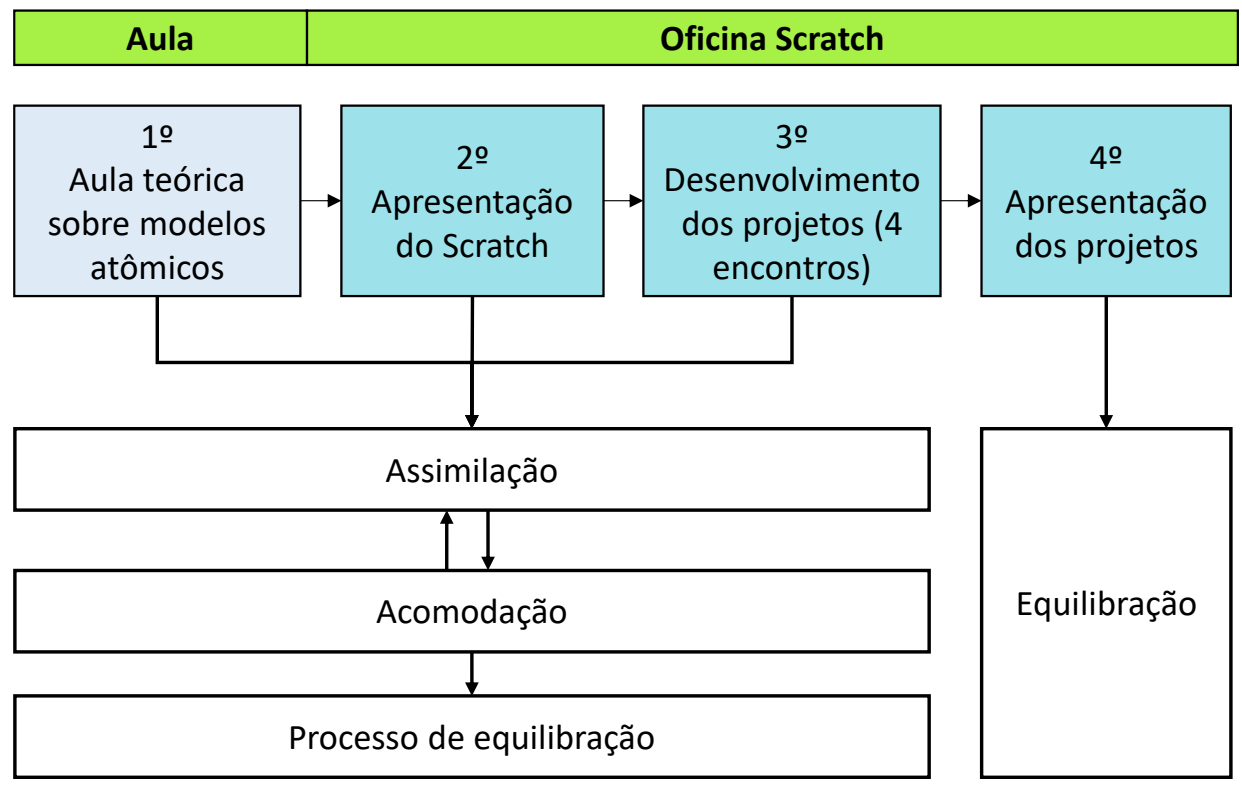

Fonte: os Autores

A Figura 1 representa o processo de aquisição de um conhecimento específico caso este fosse passível de observação. Como se pode perceber, a assimilação ocorre sempre que o indivíduo entra em contato com uma nova informação, que deixa de ser uma desconhecida novidade após a sucessão de atuações em conjunto de assimilações e acomodações. É observável também que há um duplo sentido entre a assimilação e a acomodação, isso porque não há uma sequência necessária que elenca um e outro, mas são processos que se afetam mutuamente, sucessivamente.

Assim, de acordo com a figura 1 é possível perceber como, embora a assimilação pareça ocorrer antecipadamente diante de uma nova informação, é necessário que logo em seguida ocorra uma acomodação, para que aquele conteúdo assimilado possa ser realmente adaptado às estruturas cognitivas.

É demonstrado também que a equilibração é uma busca constante. Desde o momento em que o sujeito se vê diante de uma nova demanda do meio, se mostra desadaptado em relação a este, sendo então levado a buscar esta adaptação, que se mostrou suficiente (em relação a demanda específica referente ao experimento) no momento em que todas as equipes foram capazes de desenvolver jogos e simulações com o software Scratch, demonstrando aprendizado tanto no desenvolvimento da programação, como na aquisição de conhecimento sobre modelos atômicos. Ilustrando 
um método que respeite os preceitos construtivista e, consistentemente embasado a cada etapa.

\section{DESCRIÇÃO DOS SUJEITOS DA PESQUISA}

A pesquisa foi desenvolvida no Instituto Federal do Amazonas (IFAM), Campus Presidente Figueiredo. Os sujeitos foram alunos regularmente matriculados na primeira série do ensino médio técnico, do curso de Desenvolvimento de Sistemas, selecionados mediante convite e sorteio, além disso, os participantes tiveram que assinar e entregar o TCLE (Termo de Consentimento Livre e Esclarecido) dos pais ou responsáveis e TCLE individual do aluno. O TCLE garantiu o anonimato dos alunos e confidencialidade dos dados coletados.

O sorteio ocorreu em sala de aula no dia 13 de fevereiro de 2019, após a apresentação da pesquisa e da realização do convite. Em razão da baixa quantidade de computadores disponíveis na sala de informática da Instituição, optou-se por selecionar doze estudantes, porém, apenas nove deles permaneceram participando das oficinas. Os que ficaram foram denominados de: E1(estudante 1); E2 (estudante 2); E3 (estudante 3); E4 (estudante 4); E5 (estudante 5); E6 (estudante 6); E7(estudante 7); E8 (estudante 8); E9 (estudante 9).

\section{OFICINA SCRATCH}

As oficinas ocorreram em seis encontros, uma vez por semana, num contraturno, das 13 às 17 horas, no período de fevereiro a abril de 2019. Foram organizadas 4 equipes e como regra ficou estabelecido que cada grupo ficasse responsável por um modelo atômico.

Além disso, para avaliar o aprendizado dos alunos, propusemos nove encontros de desenvolvimento das ideias com a utilização do Scratch. Quatro desses encontros basearam na criação dos sistemas com a temática de modelos atômicos. Em particular o primeiro encontro consiste na apresentação do projeto a referida turma; o segundo encontro consistiu na aula teórica sobre modelos atômicos, foi apresentado os principais cientistas, as estruturas atômicas de Dalton, Thomson, Rutherford e Bohr, assim como as partículas subatômicas do átomo: próton, nêutrons e elétrons. 
No terceiro encontro foi realizada a aplicação do questionário inicial, organização e divisão das equipes, isto posto, como resultado da formação dos alunos obtivemos três equipes. Na equipe 1 estavam os estudantes E3, E7 e E9; na equipe 02 os estudantes E4, E5 e E6 e na equipe 03 os estudantes E1, E2 e E8.

No quarto encontro se deu a apresentação do Scratch, ou seja, o propósito de criação, como funciona a programação em blocos e amostras de exemplos criativos desenvolvidos com o programa. No quinto, sexto, sétimo e oitavo encontro os alunos desenvolveram os projetos, eles procuraram flexibilizar o casamento entre o conteúdo proposto e as funções disponíveis no Scratch. E então no nono e último encontro ocorreu a apresentação dos projetos. O Quadro 1 a seguir apresenta a relação dos encontros com as atividades. $\mathrm{O} 4^{\circ}, 5^{\circ}, 6^{\circ}, 7^{\circ}, 8^{\circ}$ e $9^{\circ}$ encontro configuram-se na oficina Scratch.

Quadro 1 - Relação das atividades realizadas nos encontros de aplicação da pesquisa

\begin{tabular}{|c|c|c|c|c|}
\hline Semanas & & Encontros & Data & Atividades realizadas \\
\hline Semana 1 & \multirow{3}{*}{ 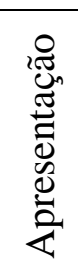 } & $1^{o}$ & $13 / 02 / 2019$ & Apresentação do projeto \\
\hline Semana 2 & & $2^{\circ}$ & $20 / 02 / 2019$ & Aula teórica de química \\
\hline Semana 3 & & $3^{\circ}$ & $27 / 02 / 2019$ & $\begin{array}{c}\text { Divisão das equipes e aplicação } \\
\text { do questionário inicial }\end{array}$ \\
\hline Semana 4 & \multirow{6}{*}{ 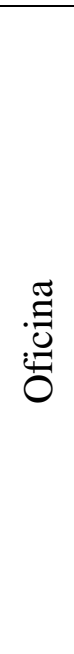 } & $4^{\circ}$ & 13/03/2019 & Apresentação do Scratch \\
\hline Semana 5 & & $5^{\circ}$ & 20/03/2019 & $\begin{array}{c}\text { Desenvolvimento dos projetos - } \\
\text { Parte } 1\end{array}$ \\
\hline Semana 6 & & $6^{\circ}$ & $27 / 03 / 2019$ & $\begin{array}{c}\text { Desenvolvimento dos projetos - } \\
\text { Parte } 2\end{array}$ \\
\hline Semana 7 & & $7^{\circ}$ & 03/04/2019 & $\begin{array}{c}\text { Desenvolvimento dos projetos - } \\
\text { Parte } 3\end{array}$ \\
\hline Semana 8 & & $8^{\circ}$ & 10/04/2019 & $\begin{array}{l}\text { Desenvolvimento dos projetos - } \\
\text { parte } 4\end{array}$ \\
\hline Semana 9 & & $9^{\circ}$ & $17 / 04 / 2019$ & $\begin{array}{c}\text { Apresentação dos projetos dos } \\
\text { alunos }\end{array}$ \\
\hline
\end{tabular}

Fonte: os Autores

Nas oficinas os alunos estavam livres para interagir com os seguintes instrumentos técnicos: aparelhos celulares (individuais), computadores (da sala de informática) e livros didáticos. A atividade também permitiu a proximidade entre alunos e professor, durante a mediação. Todas as interações apresentadas estruturam a Figura 2 abaixo. 
Figura 2 - Relação das atividades realizadas nos encontros de aplicação da pesquisa

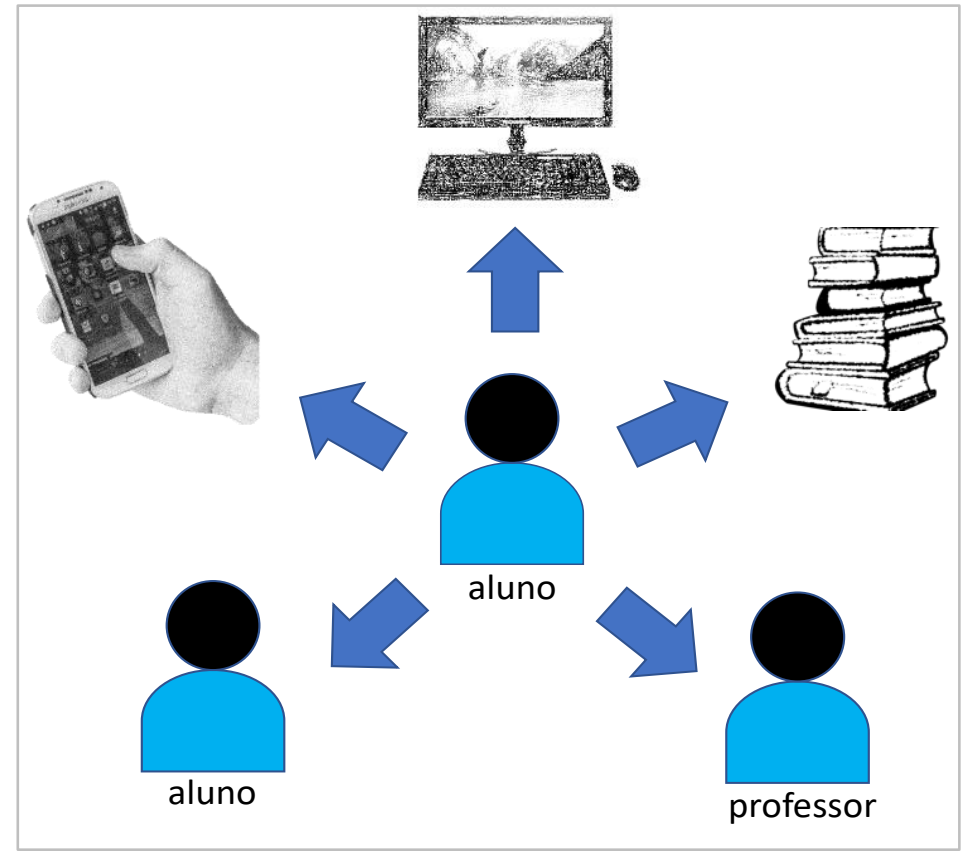

Fonte: os Autores

A Figura 2 representa a relação do usuário (estudante) com o meio, durante a oficina Scratch. O avatar do aluno localizado no centro representa o estudante participante da pesquisa, mostrando que ele é ativo na atividade e que interage com o aparelho celular, computador e livros de química e sites que abordam sobre o funcionamento do programa Scratch. A atividade também permite a interação direta com os demais colegas, também participantes, e com o professor.

\section{COLETA DOS RESULTADOS}

A coleta e análise dos resultados ocorreu nas seguintes situações: no $3^{\circ}$ encontro, com a aplicação do questionário inicial para verificar o conhecimento prévio dos estudantes acerca do tema; no $5^{\circ}, 6^{\circ}, 7^{\circ}$ e $8^{\circ}$ encontro, durante a oficina, para observação a participação e desempenho dos estudantes; e no $9^{\circ}$ encontro, durante a apresentação dos projetos e pela aplicação de um questionário final.

De acordo com De Pádua (p. 77, 2016) “o questionário é um instrumento de coleta de dados que são preenchidos pelos informantes, sem a presença do pesquisador”.

As questões definidas no questionário inicial foram:

1. Já estudou o conteúdo de modelos atômicos? Se sim, cite-os. 
2. O que significa átomo para você?

3. Observe as imagens e diga o nome dos modelos atômicos.

O aprendizado do conteúdo proposto assim como a habilidade com programação foi verificado durante a apresentação dos projetos.

As questões estabelecidas no questionário final foram:

1. Você interagiu mais com a aula expositiva do professor ou com o uso de recursos de Scratch?

2. O que essa pesquisa trouxe de diferente para o seu aprendizado relacionado ao estudo dos modelos atômicos?

\section{RESULTADOS E DISCUSSÃO}

Durante a oficina foi orientado aos estudantes para que se cadastrassem e acessassem a plataforma Scratch no site https://scratch.mit.edu/explore/projects/all, para que tivessem acesso aos inúmeros projetos dispostos na página, desenvolvidos por estudantes, educadores e pesquisadores, para que pudessem auxiliá-los durante o desenvolvimento de suas ideias.

No momento da oficina (Figura 3) cada estudante dispunha de um computador e era livre para deslocar-se e interagir com os demais integrantes de sua equipe.

Figura 3 - Prática da oficina Scratch

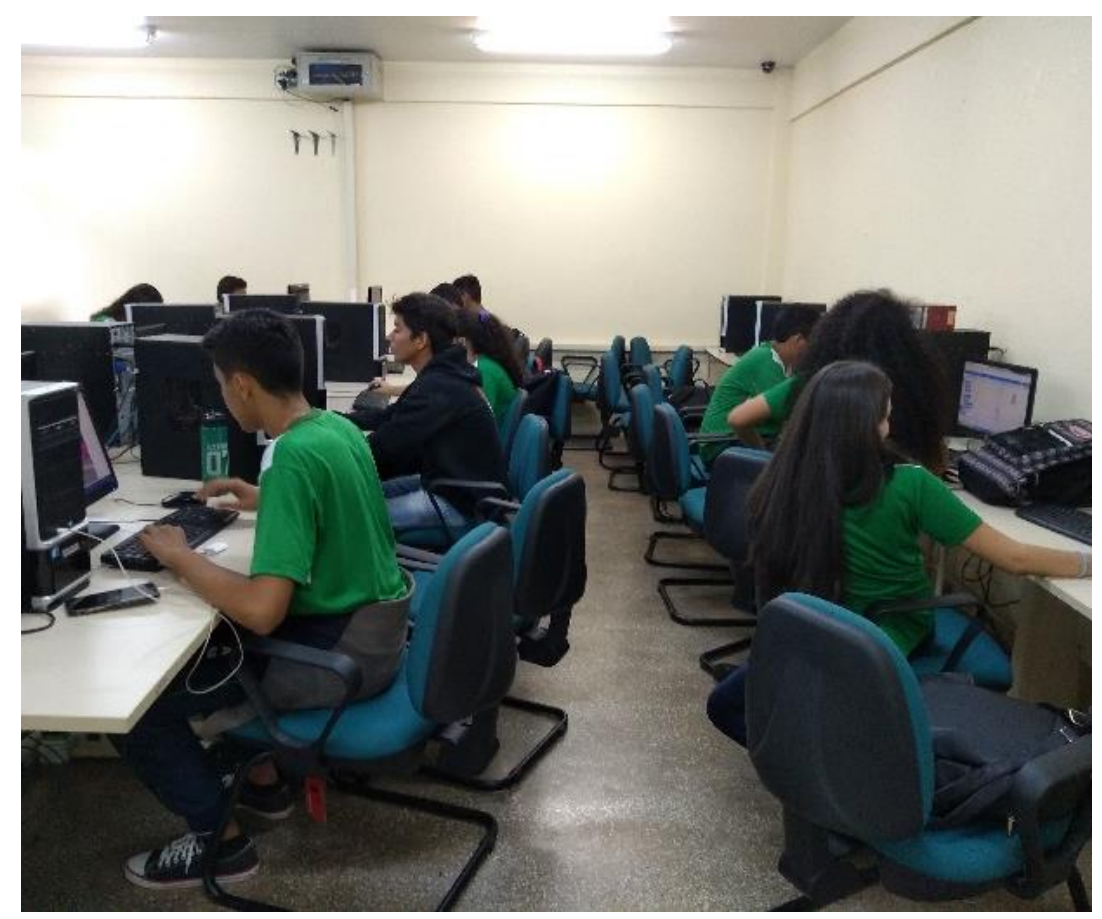


O resultado da análise dos conhecimentos prévios dos estudantes acerca do conteúdo de modelos atômicos, coletado por meio do questionário inicial, é apresentado no Quadro 2 a seguir.

Quadro 2 - Relação das atividades realizadas nos encontros de aplicação da pesquisa

\begin{tabular}{|c|c|c|c|}
\hline Estudantes & $\begin{array}{l}\text { Já estudou sobre os } \\
\text { modelos atômicos? } \\
\text { Se sim, cite-os }\end{array}$ & $\begin{array}{l}\text { O que significa } \\
\text { átomo para você? }\end{array}$ & $\begin{array}{c}\text { Observe as imagens } \\
\text { e diga o nome dos } \\
\text { modelos atômicos }\end{array}$ \\
\hline E1 & $\begin{array}{l}\text { Dalton, Thomson, } \\
\text { Rutherford e Bohr }\end{array}$ & $\begin{array}{c}\text { Uma parte } \\
\text { indivisível da } \\
\text { matéria } \\
\end{array}$ & $\begin{array}{l}\text { Acertou todos os } \\
\text { modelos }\end{array}$ \\
\hline $\mathbf{E 2}$ & Dalton e Rutherford & $\begin{array}{c}\text { É última partícula do } \\
\text { qual foi derivada de } \\
\text { partes menores }\end{array}$ & $\begin{array}{c}\text { Acertou os modelos } \\
\text { de Dalton, Thomson } \\
\text { e Bohr }\end{array}$ \\
\hline $\mathbf{E 3}$ & $\begin{array}{l}\text { Dalton, Thomson, } \\
\text { Rutherford e Bohr }\end{array}$ & $\begin{array}{c}\text { Uma parte } \\
\text { indivisível da } \\
\text { matéria }\end{array}$ & $\begin{array}{l}\text { Acertou todos os } \\
\text { modelos }\end{array}$ \\
\hline E4 & Nunca estudei & Algo bem pequeno & $\begin{array}{c}\text { Acertou o modelo de } \\
\text { Thomson }\end{array}$ \\
\hline E5 & $\begin{array}{l}\text { Dalton, Thomson, } \\
\text { Rutherford e Bohr }\end{array}$ & $\begin{array}{l}\text { Menor unidade } \\
\text { existente }\end{array}$ & $\begin{array}{l}\text { Acertou todos os } \\
\text { modelos }\end{array}$ \\
\hline E6 & Nunca estudei & Algo bem pequeno & $\begin{array}{l}\text { Acertou o modelo de } \\
\text { Thomson }\end{array}$ \\
\hline E7 & Nunca estudei & $\begin{array}{c}\text { Partículas pequenas } \\
\text { que não é possível } \\
\text { enxergar }\end{array}$ & $\begin{array}{c}\text { Acertou os modelos } \\
\text { de Dalton e } \\
\text { Thomson }\end{array}$ \\
\hline E8 & $\begin{array}{l}\text { Dalton, Thomson, } \\
\text { Rutherford e Bohr }\end{array}$ & Algo não divisível & $\begin{array}{l}\text { Acertou todos os } \\
\text { modelos }\end{array}$ \\
\hline E9 & Nunca estudei & $\begin{array}{c}\text { Partículas pequenas } \\
\text { e que não se pode } \\
\text { destruir }\end{array}$ & $\begin{array}{l}\text { Acertou os modelos } \\
\text { de Thomson e Bohr }\end{array}$ \\
\hline
\end{tabular}

Fonte: os Autores

Em relação a primeira questão "Já estudou sobre os modelos atômicos? Se sim, cite-os", as respectivas respostas teriam de ser: o modelo planetário (de Bohr), o pudim de passas (de Thomson), a bola de bilhar (de Dalton) ou apenas o nome dos cientistas, pois atribuir o modelo ao nome do pesquisador responsável também é considerado correto. 
Assim, foi observado que dentre os 9 estudantes participantes apenas 4 responderam corretamente, foram eles o E1, E3, E5 e E8 e 4 relataram que não tinham conhecimento do assunto, sendo eles os estudantes E4, E6, E7 e E9. E somente um estudante obteve uma resposta incompleta, foi o estudante E2.

Para a segunda questão "O que significa átomo para você?" foi observado diferentes tipos de respostas, mas todas coerentes com a pergunta. Aos estudantes E9, E8, E5 e E2 daremos um certo destaque pois apresentaram respostas completas. Os demais estudantes apresentaram respostas vagas ou genéricas.

Para a terceira questão "Observe as imagens e diga o nome dos modelos atômicos" foi utilizada a Figura 4 abaixo.

Figura 4 - Modelos atômicos

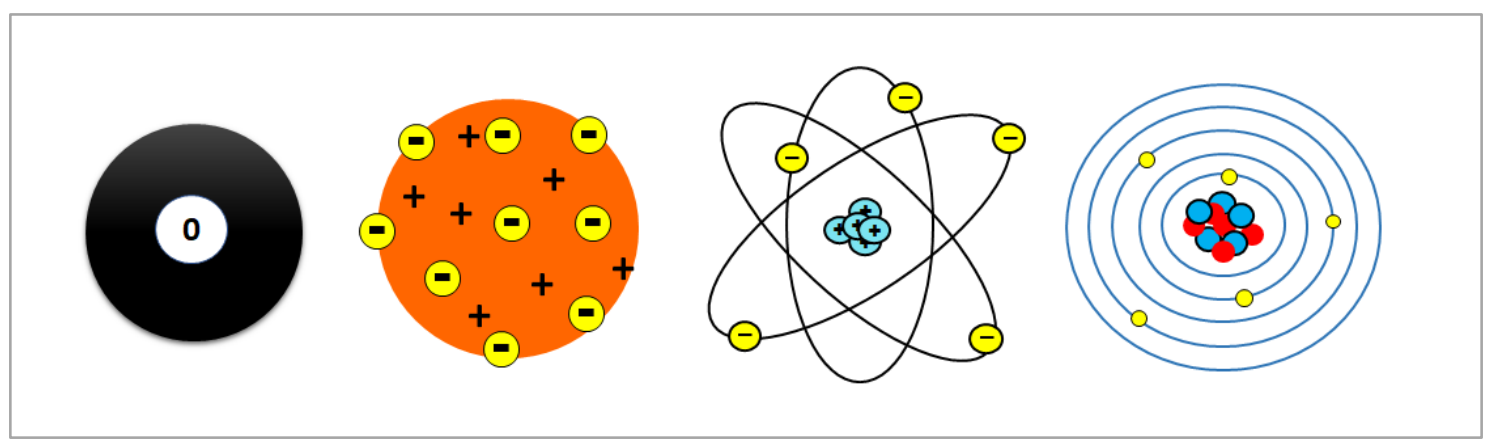

Fonte: os Autores

Dentre as respostas obtidas, apenas os estudantes E1, E3, E5 e E8 souberam nomear corretamente os respectivos átomos, os demais acertaram três ou dois modelos, O que demonstra a memorização dos modelos e não o desenvolvimento da aprendizagem e do processo de equilibração, pois nas duas perguntas anteriores observamos respostas incompletas, o que não teria acontecido se tivessem desenvolvido a equilibração.

\section{RESULTADOS DA OFICINA SCRATCH}

As exposições das criações desenvolvidas pelos alunos revelam as habilidades com programação aprendidas na criação do conteúdo de modelos atômicos, e podem ser visualizadas nas Figuras 5, 6, 7 a seguir. 
As apresentações se deram pela ordem das equipes, e as três equipes participantes optaram por desenvolver animações com os modelos de Dalton, Rutherford e Bohr. O modelo de Thomson não foi apresentado.

Figura 5 - Produção da Equipe 01

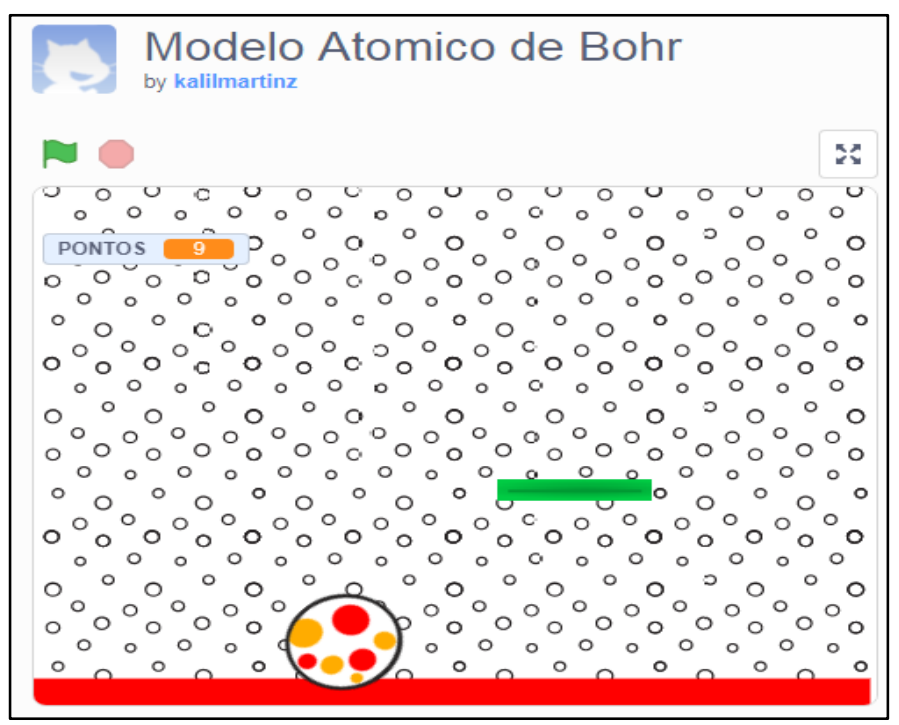

Fonte: os Autores

A equipe 01, expôs o modelo atômico de Bohr, como foi apresentado na Figura 5 o Template do jogo.

O jogo tinha como objetivo impedir o "salto" eletrônico do elétron, representado pela bolinha colorida, e para isso existia a barra verde que se movimentava da direita para a esquerda, com a utilização do mouse. Caso a bola saltasse o usuário perdia pontos. Então, o usuário controlava a barra verde para impedir o salto da bolinha colorida.

Para eles, esse campo da imaginação nos leva a crer que esses estudantes entenderam o modelo atômico proposto pelo cientista Bohr, uma vez que esse cientista explica a energia quantizada do elétron que só se movimenta dentro de uma órbita estacionária com energia fixa e constante.

A equipe 02 apresentou o modelo atômico de Rutherford por meio de uma simulação. A Figura 6 a seguir apresenta o produto desenvolvido pelos estudantes, sendo possível visualizar um esquema de movimentação dos elétrons, representados pelas bolinhas de cor azul claro encima das linhas circulares de cor azul escuro, essas linhas representavam orbitas. As bolinhas de cores laranjas e vermelhas representaram o núcleo do átomo. 
Figura 6 - Produção da Equipe 02

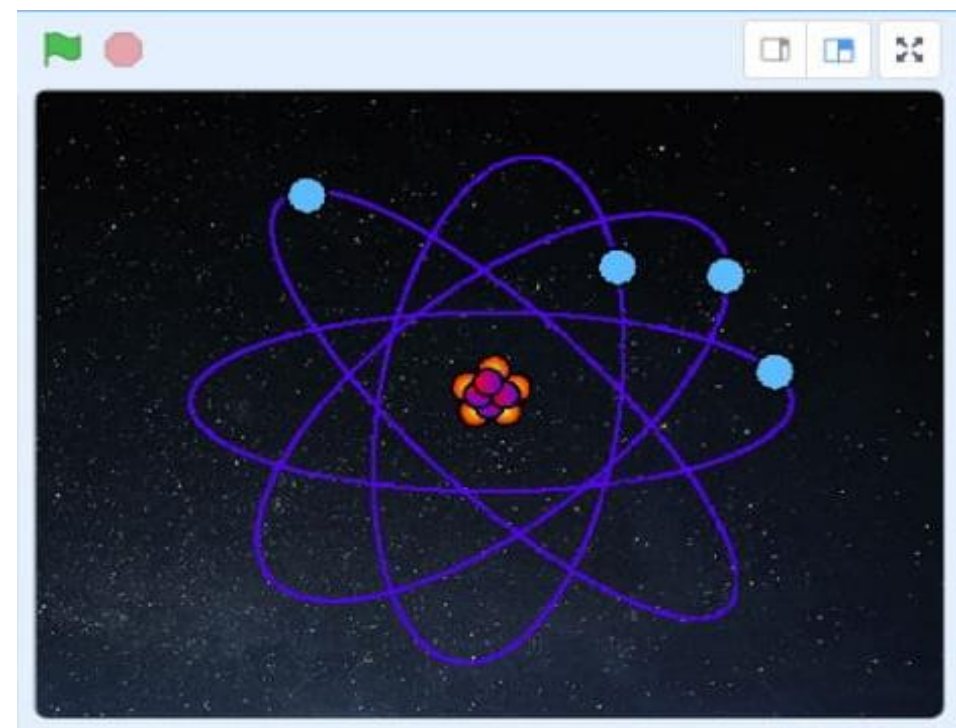

Fonte: os Autores

Dessa forma, percebe-se que a equipe compreendeu o modelo científico elaborado por Rutherford. Durante a exposição ficou esclarecido, por meio de suas falas, que esse modelo atômico é comparado a um sistema planetário.

Já a equipe 03 tomou a decisão de criar um quiz com base no modelo atômico de Dalton. A Figura 7 a seguir é demonstrado o resultado do jogo QUIZ IDES.

Figura 7 - Produção da Equipe 03

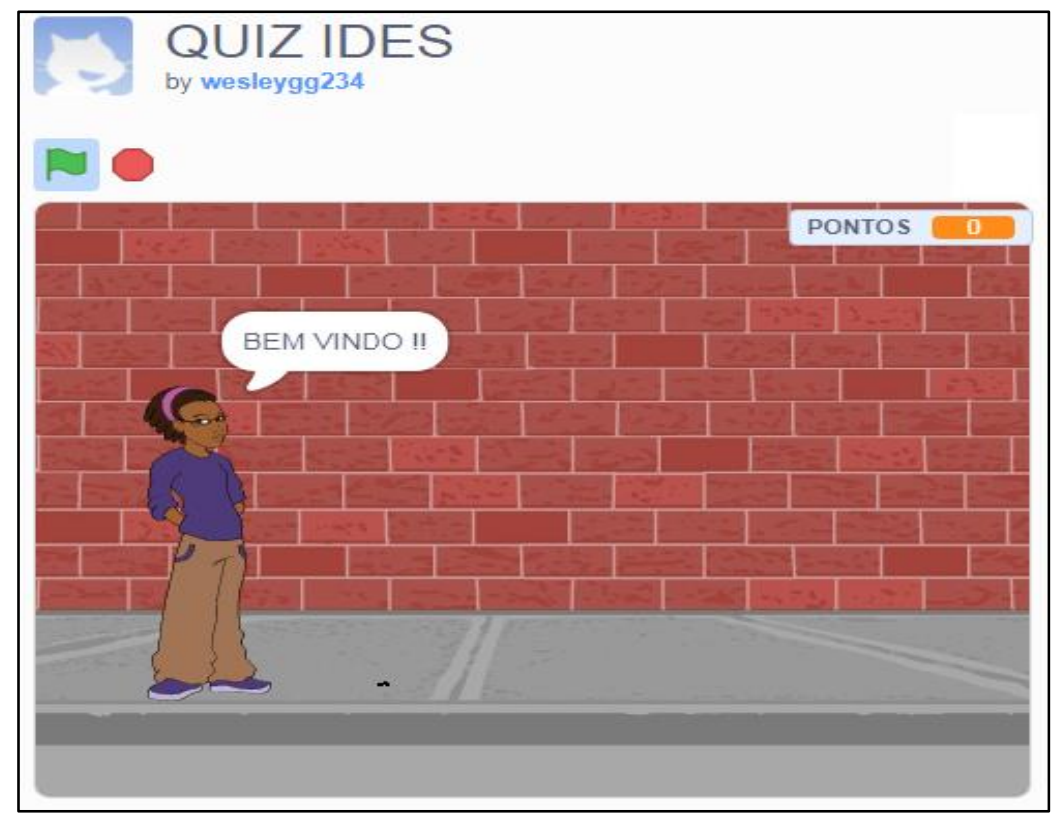

Fonte: os Autores 
Nesse quiz, as perguntas permitiram que o usuário, por meio dos erros e acertos, entendesse sobre o modelo atômico de Dalton. No jogo havia apenas 4 perguntas onde os estudantes destacam as principais observações feitas por Dalton, como a de que o átomo é comparado a uma bola de bilhar, uma esfera rígida, maciça e indestrutível.

Assim, de acordo com os comandos criados pelos estudantes através da lógica de programação, durante a jogabilidade o jogador interage com o personagem que aparece no template da Figura 7, sendo ele o detentor das perguntas. Ao clicar na tela com o mouse as questões aparecem, se errar perde pontos e aparece a mensagem "errado", e se acertar ganha pontos e aparece a mensagem "certo" e assim segue para a próxima pergunta.

Ademais, na apresentação dos trabalhos, realizada no $9^{\circ}$ encontro, cada equipe teve um prazo de dez minutos para exposição. A transcrição das falas encontra-se no Quadro 3 a seguir.

Quadro 3 - Registro das falas dos estudantes durante as apresentações

\section{Equipe 1}

\section{Exposição do E3}

"Boa tarde gente, a gente escolheu o modelo de Bohr, esse modelo de Bohr é representado por um núcleo pequeno e nele tem uma órbita circular que são as camadas $\mathrm{K}, \mathrm{L}, \mathrm{M}$, e cada camada tem uma certa quantidade de elétrons, aí os elétrons vão e pulam de uma camada para outra ao ganhar energia, aí eles voltam para a camada original e devolve essa energia na forma de luz, a gente fez esse modelo no Scratch, isso aqui é um elétron, isso aqui é uma camada, essa parte vermelha, a gente fez um joguinho, onde essa marquinha do passar para outra camada"

\section{Exposição do E7}

"O físico dinamarquês Niels Bohr deu continuidade ao trabalho desenvolvido por Rutherford, ele preencheu a lacuna que existia na teoria atômica proposta por Rutherford, por esse motivo o átomo é chamado modelo atômico de Rutherford-Bohr"

\section{Exposição do E9}

“A programação no código do jogo temos dois elementos, o átomo de Bohr (a bola) e o paddle (a barra). No código do átomo temos os comandos, quando a tecla espaço for pressionada aponte para a direção de 45 graus, sempre mover 20 passos, se tocar na cor vermelha então vai parar tudo, e se tocar na borda vai voltar. E o outro é quando a tecla espaço for pressionada mude pontos para 0 (zero), sempre se tocado em paddle então vai adicionar 1(um) ponto e vai girar 100 graus para a esquerda e espere 1(um) segundo. Já no código do paddle, temos quando a tecla espaço for pressionada, sempre vá para o ponteiro do mouse".

\section{Equipe 2}

\section{Exposição do E1}


Boa tarde, a gente está aqui para fazer a apresentação da nossa animação, e a nossa animação gira em torno do modelo atômico de Rutherford", esse teórico chegou a uma experiência onde ele usou uma fonte de radiação alfa, um contador Geiger e uma lâmina de oura para ser bombardeada pelas partículas alfa, nesse experimento ele percebeu que a maioria das partículas alfa atravessavam a lâmina de ouro, e apenas alguns voltavam, ele concluiu que o átomo é formado por mais espaços vazios do que preenchidos, e ali estariam os elétrons".

"A nossa animação ele gira em torno de comandos feitos automaticamente no programa Scratch através do espere, e com isso vai mudando as aparências e os cenários, e o principal comando que faz esses elétrons girarem em torno do núcleo é o deslize, seria deslize por um segundo até determinada posição entre $\mathrm{x}$ e y, programamos uma animação que estabelece uma comparação clara e simples e objetiva do sistema solar com o modelo atômico de Rutherford. Os determinados códigos que ordenamos para cada ator são comuns dentro de uma animação não muito extensa, tendo como foco principal os setores de movimentação, de aparência e de controle. Na parte da movimentação usamos as funções: deslize por determinado tempo entre as posições de x e y (para proporcionar uma locomoção aos elétrons e aos planetas). A função vá para a localização entre os eixos x e y (para organizar os atores sempre que a animação começar). A função gire $\mathrm{x}$ (para ajeitar os ângulos dos planetas na rotação), e mova x passos (para auxiliar na locomoção dos atores). Na seção da aparência utilizamos as eminentes funções: mostre e esconda (para a transição de cenários e atores) e próxima fantasia (para dar espaço a novos atores). No setor de controle aplicamos as funções: sempre (para resumir os códigos de alguns atores). Espere x segundos (para especificar o tempo de ação de cada ator, e o tempo de mudança de cenário). E repita determinadas vezes (para deixar a rotação de alguns planetas mais precisa".

\section{Exposição do E2}

"Vamos comparar o sistema solar com esse modelo atômico, porque o sistema solar ele tem o sol como o núcleo e os planetas ao redor, que seriam os elétrons."

\section{Exposição do E8}

"O script do jogo foi baseado no se sim e se não, caso a resposta esteja certa, vai adicionar 10 pontos na variável ponto, se caso a pessoa erre, ele zera os pontos, quando eu estava fazendo esse script eu achei um erro, que eu não estava conseguindo consertar, que era que o jogo só acertava uma resposta para cada pergunta, tipo, vamos supor, como foi comparado o modelo de Dalton, resposta uma bola de bilhar, não aceitava as duas respostas"

\section{Equipe 3}

\section{Exposição do E4}

"Boa tarde, o nosso grupo vai falar sobre o modelo de Thompson e Dalton".

\section{Exposição do E5}


"Pois é, nós criamos um quiz baseado nos modelos atômicos Dalton e Thompson, e eu vou falar um pouco sobre Dalton, Dalton ele criou um modelo que ele comparou o átomo a uma bola de bilhar, e ele quebrou a ideia de que o mundo era composto por substância indivisível que era chamada de átomo, quando ele descobriu, ele provou que o mundo tinha o átomo, só que não era uma substância, e ele não era invisível, ele era visível só que era minúsculo, e foi Thompson que descobriu o elétron"

\section{Exposição do E6}

"Thompson foi o descobridor do elétron e da relação entre a carga e a massa do elétron, e esse modelo ficou conhecido como pudim de passas"

Fonte: os Autores

Diante da exposição dos estudantes percebe-se que ocorreu aprendizado acerca do tema. Verificou-se também que tiveram êxito em usar o programa Scratch, fato que é comprovado no Quadro 4 a seguir, com as perguntas investigativas realizadas durante a exposição.

Quadro 4 - Resultado do questionário final

\begin{tabular}{|c|c|c|}
\hline Estudantes & $\begin{array}{l}\text { Você interagiu mais com a } \\
\text { aula expositiva do } \\
\text { professor ou com o uso de } \\
\text { recursos de Scratch? }\end{array}$ & $\begin{array}{l}\text { O que essa pesquisa trouxe de diferente } \\
\text { para o seu aprendizado relacionado ao } \\
\text { estudo dos modelos atômicos? }\end{array}$ \\
\hline E1 & $\begin{array}{l}\text { Interagindo, além disso, } \\
\text { como por exemplo buscando } \\
\text { em outras fontes de } \\
\text { informação }\end{array}$ & $\begin{array}{l}\text { Trouxe muitos detalhes mínimos, que as } \\
\text { vezes nós deixamos escapar, quando não } \\
\text { prestamos atenção totalmente focada para o } \\
\text { assunto. }\end{array}$ \\
\hline E2 & $\begin{array}{llr}\text { Tecnologia } & \text { sempre } & \text { é } \\
\text { importante } & \text { e fácil de } \\
\text { trabalhar, } & \text { então ajuda } \\
\text { bastante" } & & \end{array}$ & $\begin{array}{l}\text { Eu nunca tinha usado Scratch e foi } \\
\text { interessante desenvolver jogos, animações, } \\
\text { e eu aprendi coisas que eu não sabia, pois } \\
\text { foi um estudo avançado }\end{array}$ \\
\hline E3 & $\begin{array}{l}\text { Eu aprendo mais com } \\
\text { recursos oferecidos pela } \\
\text { tecnologia }\end{array}$ & $\begin{array}{l}\text { Essa pesquisa me ajudou a entender melhor } \\
\text { os modelos atômicos e foi mais fácil } \\
\text { compreender como eles funcionam, qual foi } \\
\text { o pensamento dos químicos ao } \\
\text { desenvolverem os modelos, (...) }\end{array}$ \\
\hline E4 & $\begin{array}{l}\text { Eu aprendi muito mais com a } \\
\text { ajuda da tecnologia e o } \\
\text { programa Scratch me ajudou } \\
\text { bastante na parte }\end{array}$ & $\begin{array}{l}\text { O programa Scratch me ajudou na parte } \\
\text { prática, e com as pesquisas que tive que } \\
\text { fazer por causa do jogo. }\end{array}$ \\
\hline E5 & Com interação externa & $\begin{array}{l}\text { Eu não conhecia o app/site Scratch que } \\
\text { facilitou o aprendizado de algoritmo, matéria } \\
\text { que tenho dificuldade. }\end{array}$ \\
\hline E6 & $\begin{array}{l}\text { Interagindo além das aulas } \\
\text { dele }\end{array}$ & $\begin{array}{l}\text { Trouxe os mínimos detalhes que eu não } \\
\text { consegui aprender nas aulas do nono ano } \\
\text { como as conclusões que os cientistas }\end{array}$ \\
\hline
\end{tabular}




\begin{tabular}{|c|c|c|}
\hline & & $\begin{array}{l}\text { adquiriram nos seus modelos atômicos } \\
\text { através de seus próprios estudos }\end{array}$ \\
\hline E7 & $\begin{array}{l}\text { Aprendo melhor com a } \\
\text { interação }\end{array}$ & $\begin{array}{l}\text { Eu pude entendê-los melhor, entender como } \\
\text { eles funcionam e como foram reproduzidas } \\
\text { a descoberta }\end{array}$ \\
\hline E8 & $\begin{array}{l}\text { Eu não tive dificuldade em } \\
\text { aprender o programa } \\
\text { Scratch, e eu gostei e } \\
\text { aprendi muito mais assim }\end{array}$ & Aprendi de uma forma diferente, gostei \\
\hline E9 & $\begin{array}{l}\text { Interagindo com os recursos } \\
\text { tecnológicos que temos } \\
\text { acesso }\end{array}$ & Uma nova forma de aprender o assunto \\
\hline
\end{tabular}

Fonte: os Autores

A partir da opinião dos alunos expressa no Quadro 4 é visível que as aulas sobre os modelos atômicos por meio da implementação do Scratch se tornaram mais dinâmicas, acessíveis e, principalmente, curiosa no tocante à descoberta, à busca pelo "novo" para o aluno por meio da linguagem de blocos.

Considerando que uma concepção construtivista sugere que os alunos construam seu próprio conhecimento a partir de ferramentas iniciais nas quais eles podem se apoiar, é possível observar na opinião dos alunos que a utilização do Scratch proporcionou uma aprendizagem com mais detalhes, como citam os estudantes E1, E2 e E6. Além de um aprendizado mais completo (detalhado), os estudantes E3 e E5, caracterizaram o método como mais fácil, do que aquele aplicado tradicionalmente. As respostas dadas pelos estudantes E4 e E6 são significativas, já que foi salientado tanto o bom papel desempenhado pela prática, como proporcionou o aprendizado de um conteúdo com o qual o aluno tinha dificuldade, respectivamente.

Como discorre Pereira (2011), os recursos educativos digitais podem ser utilizados nas várias disciplinas curriculares seguindo as orientações das metas de aprendizagem. Sendo o fio condutor para desenvolver a criatividade e concentração de alunos mais motivados para novas aprendizagens, através de animações, imagens, sons, simulações. Gabriel (2020) mencionam que a utilização de ferramentas lúdicas para o ensino e aprendizagem possuem as seguintes qualidades: tornam as tarefas prazerosas, desafiadoras, possuem dimensão simbólica e não limitam as possibilidades de criação e recriação.

É possível observar nas atividades desenvolvidas que os conceitos piagetianos permearam cada etapa, por exemplo, o desenvolvimento de jogos e simulações através da programação com o Scratch não seria possível se a cognição dos alunos não fosse capaz 
de atuar tanto em nível operatório concreto, como a nível lógico-formal, noções que são observadas no manuseamento de imagens visuais e no facilidade com que os alunos conseguiram articular conceitos científicos abstratos, assim como as abstrações empíricas e reflexionantes também se mostraram presentes ao longo do processo de equilibração.

\section{CONSIDERAÇÕES FINAIS}

O Scratch possui características lúdicas que auxiliam no aprendizado de programação e de diferentes temas da educação básica, isso geralmente ocorre quando o utilizam como ferramenta de produções recreativas e interativas, no qual o aluno é o ator da atividade, auxiliando, por sua vez, no processo de ensino e aprendizado e no desenvolvimento da assimilação, acomodação e equilibração.

A datar do mapeamento em pesquisas relacionadas com Scratch no ensino de ciências, que envolvessem a ação discente na criação de jogos, simulações e animações, foi possível planejar como se daria o processo da construção do conhecimento durante a prática criativa no Scratch. Assim, a partir da pesquisa realizada, foi possível aplicar o Scratch e mapear a assimilação, acomodação e equilibração nas atividades em grupo.

Os resultados apontam que as produções criadas pelos alunos durante as oficinas contribuíram para o ensino e aprendizado dos modelos atômicos, para mais, a programação em blocos serviu de subsídios para o entendimento da lógica de programação, necessária para uma turma inicial do curso técnico em desenvolvimento de sistema. A verificação do aprendizado de modelos atômicos foi observada na apresentação dos resultados conquistados durante a oficina.

Diante do exposto, percebe-se a necessidade de investigar outros tipos de conteúdos na disciplina de química, principalmente os de difícil assimilação e compreensão. Ademais, a pesquisa apresentou uma lacuna, no que se refere a aplicação do questionário final, onde não foram repetidas as perguntas aplicadas no questionário inicial sobre o conteúdo de química, o que teria sido de suma importância para realizar uma comparação do resultado do questionário, antes e após a oficna. Apesar disso, na apresentação pode-se verificar o aprendizado acerca do tema.

Isto posto, esse trabalho de pesquisa contribuiu para a investigação quanto ao uso do Scratch para o ensino de modelos atômicos, na disciplina de química, assim como na contribuição do desenvolvimento dos processos de assimilação, acomodação e 
equilibração nos alunos. O Scratch pode ser inserido nas escolas públicas, viabilizando tornar o aluno mais ativo no processo de aprendizado. A criatividade é essencial para o aprendizado e deve ser imbuída nos espaços educativos.

\section{REFERÊNCIAS}

BARRETO, A. M. P., DA SILVA, M. A. G. T., GIACOMINI, R., \& CARDOSO, S. L. Mediando a aprendizagem do ensino de Química na Pedagogia Democrática apoiado na tecnologia digital. In ATAS DO 90 CONGRESSO INTEGRADO DA TECNOLOGIA DA INFORMAÇÃO. Campos dos Goytacazes, RJ, 2017.

BAYTAK, A., \& LAND, S. M. An investigation of the artifacts and process of constructing computers games about environmental science in a fifth grade classroom. Educational Technology Research and Development, v. 59, n.6, 765-782, 2011.

CONCEIÇÃO, J. H. C. da., \& VASCONCELOS, S. M. Jogos Digitais no ensino de Ciências: contribuição da ferramenta de programação Scratch. Revista Areté, v. 11, n. 24, 160-185, 2018.

DE PÁDUA, E. M. M. Metodologia da pesquisa: abordagem teórico-prática. Campinas, SP: Papirus, 2016.

DO NASCIMENTO, F. G. M., \& COSTA, T. do R. O uso do scratch no ensino de química: uma possibilidade para o ensino de nomenclatura de hidrocarbonetos. Ponta Grossa, PR: Atena Editora, 2020. p. 13-20.

GABRIEL, C. T. Competências leitoras: uma análise da BNCC na busca pela Educação literária. Claraboia, v. 1, n. 13, 159-175, 2020.

GARCIA, S. M. S. A construção do conhecimento segundo Jean Piaget. Ensino em ReVista, v. 6, n. 1, 17-28, 2010.

CARVALHO Jr, G. D., \& PARRAT-DAYAN, S. Recortes históricos sobre a noção de schème em Piaget: o processo de desenvolvimento de um conceito. Revista Brasileira de Estudos Pedagógicos, v. 96, n. 244, 2016.

LIMA, L. O. Piaget para principiantes. São Paulo, SP: Grupo Editorial Summus, 1980.

MALONEY, J., RESNICK, M., RUSK, N., SILVERMAN, B., \& EASTMOND, E. The scratch programming language and environment. ACM Transactions on Computing Education, v. 10, n. 4, 1-15, 2010.

MANTOAN, M. T. E. Processo de Conhecimento - Tipos de Abstração e Tomada de Consciência. Memos do NIED, v. 7, n. 27, 1-18, 1994. 
MORAN, J. M., \& VALENTE, J. A. Educação a distância: pontos e contrapontos. São Paulo, SP: Summus Editorial, 2011.

MOURA, J. S. Oficinas de aprendizagem criativa e de Scratch como metodologias ativas para o ensino-aprendizagem de Ciências. 2020. 110 f. Dissertação (Mestrado em Ensino de Ciências e Matemática). Universidade Federal do Amazonas, Manaus, Amazonas, 2020.

PEREIRA, C. I. C. da C. "Aprendo a divertir-me": tecnologias digitais em ambiente não formal de aprendizagem: um estudo exploratório com crianças de $1^{\circ}$ ano de escolaridade. 2011. 110 f. Dissertação (Mestrado em Estudos da Criança). Universidade do Minho, Largo do Paço, Braga, 2011.

PIAGET, J. Intellectual evolution from adolescence to adulthood. Human development, v. 15, n.1, 1-12, 1972. 